\section{Changing interest on sapheno- femoral junction in the new century}

\section{Stefano Ricci \\ Università Campus Bio Medico, Roma, Italy}

A Review paper entitled The saphenofemoral junction involvement in the treatment of varicose veins disease has been accepted for publication in Veins and Lymphatics. In that review I tried to analyze objectively (as far as possible) the literature trend concerning the behavior of phlebologists toward the sapheno-femoral junction (SFJ) responsibility in causing the chronic venous insufficiency (CVI). In this editorial I try to give a personal commentary.

It is astonishing how fast was, in managing CVI, the Copernican passage from absolute junction clearance to total no touch method, made by the same generation of surgeons, a kind of very conservative individuals of the human species. In particular they ought to forget their teachers' recommendations and learn Duplex assessment, technical management, local anesthesia activity, outpatient settings and finally, rearrange their ego.

This is with great evidence demonstrated by recent international guidelines for the management of varicose veins issued in the UK, US and Europe. These guidelines recommend that endovenous thermal ablation (i.e., no direct SFJ Junction treatment) should be offered before traditional surgery (i.e., SFJ high ligation over all) for the treatment of great saphenous vein reflux. ${ }^{1-3}$

As a phlebologist with a prevalent attitude to surgery, I personally had the opportunity of actively treating patients during nearly 50 years. This period has experienced the most striking changings in the way of approaching this disease and adaptation to these changings has been continuous. At the end of my medicine study (1971) stripping in general anesthesia associated to multiple incisions over varicosities was the right answer at surgery exams at the question: treatment of varices, postoperative bed resting for a week at least being the conclusion for obtaining the higher note. In the real world, stripping was a boring operation, often abundantly bleeding, of limited scientific interest, and for this entrusted to the youngest of the team happy to have the possibility of acquiring manual experience. Consequently results were doubtful in hemodynamics, and awful in cosmetics. The operation was the same for every patient as anatomic variations were not foreseen. The alternative treatment, sclerotherapy, gave similar doubtful results apart for few prima donna experiences.

The future next generation phlebologist probably will have never seen a groin dissection and a stripping device, never hospitalized a treating patient for longer than few hours; he will be able to draw (and even understand) a hemodynamic map of the varicose network using a color Duplex, but it is not sure he will have palpated and inspected the same area of interest. The target being the saphenous stem, after an endovascular procedure he will probably leave the varicosities waiting they disappear spontaneously or treat them secondarily as a cosmetic affair. Elastic stockings will be considered useless and will be substituted by plant derivate integrators. Bandages will be considered as prehistoric tool, in use by ancestors.

Between these two extremes we can still find the complete long list of possible treatments, the choice depending only in part from patient's advantage, but most from advantage of several entities as: i) the same phlebologist (economical interest); ii) the insurance company (trying to limit expenses) or Hospital Administrators (trying to enhance reimbursement); iii) the industries providing devices and drugs; iv) the industries sponsoring induced activities (hosiery, integrators).

New gadgets will continuously be invented, leaving unchanged the GSV closure rate (the same for all methods, near to $95 \%$ at 6 months), but maintaining high the costs. As underlined by M. de Maeseneer ${ }^{4}$ requirements for the introduction of a new device are far less stringent than for the introduction of a new drug. Moreover, if a new device is similar to ones that have already been approved, companies can use a fast-track system to introduce it into clinical practice, with relatively little evidence of effectiveness.

This trend is ligated to the peculiar hemodynamic behavior of the varicose disease that takes benefit from every even minimal reduction of the incompetent network in the immediate (6-12 months), so that the treating physician may always be proud of his results, recurrence occurring later on.

As a consequence, according to Mendoza ${ }^{5}$ in lots of countries the Health Professionals' income depends on their performance. The higher the income for a procedure, the higher the personal financial benefit. In poorer countries foam sclerotherapy is the best option. In high sophisticated places, the more the cost, the better the treatment, the better the income.

If this was true, next World Congress of Phlebology ought to devote one extended
Correspondence: Stefano Ricci, Università Campus Bio Medico, via Alvaro del Portillo 200, Roma, Italy.

E-mail: varicci@tiscali.it

Received for publication: 18 July 2017.

Accepted for publication: 19 July 2017.

This work is licensed under a Creative Commons Attribution 4.0 License (by-nc 4.0).

(C) Copyright S, Ricci, 2017

Licensee PAGEPress, Italy

Veins and Lymphatics 2017; 6:6927

doi:10.4081/vl.2017.6927

session to the revision of the ethics of the present general management.

At the opposite, the same peculiar hemodynamic behavior of the vein system cited may be the source of simplifying the treatment, limiting the invasiveness by: i) office setting for the great majority of actions (were possible); ii) local anesthesia (if needed); iii) limited surgery; iv) immediate ambulation; v) sparing the GSV when possible and appropriate; vi) treating the varicosities prevalently; vii) reviewing yearly the state of the limb; viii) repeat limited action when needed (Dentist like treatment).

In this perspective, and inspiring to Zamboni's editorial, ${ }^{6}$ varicosities phlebectomy and/or sclerotherapy would be the prevalent required action while GSV stem closure should be re-discussed, giving preference, when needed (i.e., more than 6-7 mm diameter, $>1$ second reflux, $>\mathrm{C} 3$, etc.) to GSV conservative treatments (CHIVA, ASVAL, isolated crossectomy), or sclerotherapy, that are cheap, do not need technical (expensive) tools, may be office based, may be easily repeated, and finally have even better cosmetic results.

In any case, SFJ is no more considered as the leading character of varicose veins drama, what is not necessarily a negative event; but the Myth disappears under the clouds of technology, that in reality is the new Myth.

A final comment and a question: development in venous treatment goes towards the invention of new technology, high costs being the moving power (laser, RF, steam, glue, industrial foam, robot?); progress in venous treatment is the search for new ways of doing simpler and cheaper (handmade foam, hook, compression, conservation). Between development and progress, what is better for our patients? 


\section{References}

1. National Institute for Health and Care Excellence. Varicose veins: Diagnosis and management. Manchester: NICE, 2013. Available from: www.nice.org.uk/guidance/cg168
2. Gloviczki P, Gloviczki ML. Guidelines for the management of varicose veins. Phlebology 2012;27:2-9.

3. Wittens C, Davies AH, Baekgaard N, et al. Management of chronic venous disease: Clinical practice guidelines of the European Society for Vascular Surgery (ESVS). Eur J Vasc Endovasc Surg
2015;49:678-737.

4. De Maeseneer M. The endovenous revolution Br J Surg 2011;98:1037-8.

5. Mendoza E. Primum non nocere. Veins and Lymphatics 2017;6:6646.

6. Zamboni P. 2016: The year of Phlebological Olympic Games. Veins and Lymphatics 2016;5:6249. 